CLINICAL STUDY

\title{
Serum adiponectin and leptin levels in relation to the metabolic syndrome, androgenic profile and somatotropic axis in healthy non-diabetic elderly men
}

\author{
Marie-Hélène Gannagé-Yared ${ }^{1}$, Simon Khalife ${ }^{3}$, Michelle Semaan ${ }^{2}$, Florence Fares ${ }^{1}$, Selim Jambart ${ }^{1}$ and \\ Georges Halaby ${ }^{1}$ \\ ${ }^{1}$ Department of Endocrinology, ${ }^{2}$ Faculty of Pharmacy, Saint-Joseph University, Beirut, Lebanon and ${ }^{3}$ Division of Clinical Pathology of the American \\ University of Beirut, Beirut, Lebanon
}

(Correspondence should be addressed to M-H Gannagé-Yared; Division of Endocrinology, Hôtel-Dieu de France Hospital, Adib Ishaac St., Beirut, Lebanon; Email: mhcyared@terra.net.lb)

\begin{abstract}
Objective: The relationships between adipocytokines, sex steroids and the GH/IGF-I axis is poorly studied and subject to controversy in healthy elderly male subjects. We investigated the association between both adiponectin and leptin, and the metabolic syndrome (MetS), lipid parameters, insulin sensitivity, sex steroids and IGF-I in healthy non-diabetic Lebanese men.

Design and methods: In this cross-sectional study, a total of 153 healthy non-diabetic men aged 50 and above (mean age 59.3 \pm 7 years) had a detailed clinical and biological evaluation. Subjects were classified according to the National Cholesterol Education Program criteria of the MetS. Insulin sensitivity was determined by the Quantitative Insulin Sensitivity Check Index (QUICKI).

Results: Subjects with the MetS had lower adiponectin and higher leptin levels $(P<0.0001$ for both variables) compared with individuals without the MetS. Adiponectin was significantly correlated with waist size, triglycerides, high-density lipoprotein (HDL) cholesterol and QUICKI $(r=-0.33,-0.26,0.45$ and 0.36 respectively, $P<0.0001$ for all variables). The relation between adiponectin and HDL cholesterol, triglycerides and QUICKI remained significant after adjustment for age and body mass index (BMI). Also, leptin was strongly correlated with waist size and QUICKI $(r=0.63$ and -0.63 respectively, $P<0.001$ for both variables). However, its relation to the lipid profile was weak (for cholesterol $r=0.16, P<0.05$; for triglycerides $r=0.17, P<0.05)$ and disappeared after adjustment for BMI. Adiponectin was positively correlated with sex hormone-binding globulin (SHBG) $(r=0.39, P<0.001)$ and inversely correlated with free-androgen index $(r=-0.24, P<0.01)$, estradiol and dehydroepiandrosterone sulfate $(r=-0.165$, $P<0.05 ; r=-0.21, P<0.01$ respectively). This difference remained significant for SHBG after adjustment for age and BMI $(r=0.20, P<0.005)$. Finally, leptin was inversely correlated with total testosterone and SHBG ( $r=-0.44, P<0.001 ; r=-0.30, P<0.001$ respectively); the relation with testosterone remained significant after adjustment for BMI. No significant relationship of either adiponectin or leptin with GH or IGF-I values was observed. In a stepwise multiple regression analysis, the independent predictors of adiponectin were HDL cholesterol, QUICKI, age and BMI $(P<0.0001, P=0.005, P=0.002$ and $P=0.047$ respectively) while for leptin, it was QUICKI, waist size and testosterone $(P<0.0001, P<0.0001$ and $P=$ 0.004 respectively). The adjusted $R^{2}$ values were 0.34 and 0.55 .

Conclusion: Our results show that in a healthy elderly male population, both adiponectin and leptin are related to insulin sensitivity, independent of age and BMI. While adiponectin is independently related to triglycerides and HDL cholesterol, the weak relationship of leptin to the lipid profile is completely mediated by BMI. In addition, and more interestingly, both adipocytokines are strongly associated with sex steroids. We speculate that SHBG is regulated by adiponectin and that there is an inhibitory effect of testosterone on the adiponectin gene. Further studies are needed to fully elucidate these relationships.
\end{abstract}

European Journal of Endocrinology 155 167-176

\section{Introduction}

Adipose tissue synthesizes several proteins involved in the regulation of insulin action and lipid metabolism. Among the proteins 'adipocytokines', adiponectin is the most abundant and exerts profound anti-diabetic, anti-atherogenic and anti-inflammatory roles (1-3). In human cross-sectional studies, plasma adiponectin levels are negatively correlated with obesity (4), waist to hip ratio (5), insulin resistance (4), dyslipidemia (6), diabetes (7) and cardiovascular disease $(8,9)$. A low plasma adiponectin level is observed in the metabolic 
syndrome (MetS) (10) and is considered as an independent risk factor for future development of type 2 diabetes (11). Conversely, leptin, which is related to body fat, is a modulator of the appetite and the energetic balance $(2,12,13)$, and could also play an important role in the genesis of the MetS and the cardiovascular disease (13-15).

The relation between sex steroids, growth hormone $(\mathrm{GH}) /$ insulin growth factor-I (IGF-I) axis and adipocytokines has recently been the subject of several reports. Adiponectin was found to be lower in men compared with women (16-17), despite an inverse relationship between estradiol and adiponectin, indicating that, in addition to estradiol, other gender-dependent factors may be of relevance. However, the relationship between testosterone and adiponectin is subject to controversy. Testosterone has been shown to decrease adiponectin levels in rodents (16). In addition, compared with eugonadal subjects, hypogonadal men have higher adiponectin levels, which are reduced by testosterone replacement therapy (18). In contrast, in a third study, testosterone administration has not been shown to affect adiponectin levels in older men with low testosterone levels (19). On the other hand, in males, negative correlations between testosterone and leptin have been shown (20-22). In all these previous studies, the relationship of adiponectin or leptin to sex hormonebinding globulin (SHBG) and free testosterone has not been studied.

The relationship between the GH/IGF-I axis and adipocytokines is also not well established and is subject to controversy. Adiponectin levels have been found to be normal $(23,24)$ or reduced $(25)$ in active acromegaly despite the insulin-resistance state of the disease. Conversely, in GH-deficient patients, an increase in adiponectin levels after recombinant growth hormone therapy was observed in two studies $(26,27)$, while a third study did not show this effect (28).

Since the relationship between adipocytokines and both sex steroids and the GH/IGF-I axis has been the subject of few and controversial reports and has never been studied in Middle-Eastern populations, the present study was performed to: i) evaluate, in our male population, the relationship of adiponectin and leptin with the components of the MetS, and ii) to clarify the relationship of both adiponectin and leptin with sex steroids (more particularly, the free-androgen index and SHBG) and the GH/IGF-I.

\section{Subjects and methods}

\section{Patients}

One hundred and fifty-three healthy Lebanese volunteers, men aged 50 and above (mean age $59.3 \pm 7$ years) were recruited to this study, which was approved by the Ethics Committee of our Hospital. After signing a written and informed consent to participate in the study, subjects provided a fasting blood sample and completed a questionnaire about their demographic characteristics, smoking status, sedentarity and present medications. We also measured their weight, height, waist and their systolic (SBP) and diastolic blood pressures (DBP) after half-an-hour of rest. The body mass index (BMI) was calculated as weight (in kilograms) over the square of the height (in squared meters). Waist circumference was measured at midway between the lower rib and the iliac crest. Exclusion criteria were diabetes mellitus (defined according to the last American diabetes association classification as a fasting glucose of more than $126 \mathrm{mg} / \mathrm{dl}$ (29)), hypogonadism or treatment with testosterone, hypopituitarism, high plasma creatinine levels (defined in our laboratory as a creatinine level higher than $15 \mathrm{mg} / \mathrm{l}$ ), a serum glutamic pyruvic transaminase (SGPT) level more than two times the upper limit of normal and any treatment with drugs that may affect insulin sensitivity such as corticosteroids and nicotinic acid. Diabetic subjects were excluded, since treatment of the disease with oral agents or insulin may affect adiponectin levels and interfere with the analysis. In addition, diabetes is a condition with lower adiponectin levels. Twenty-two patients on lipid lowering therapy were included in the study. Also, 23 subjects had coronary artery disease (based on a previous coronary angiography) and 43 were hypertensive.

The subjects were classified as metabolic syndrome positive $(\mathrm{MetS}+)$ if they met three or more of the National Cholesterol Education Program Adult Treatment Panel III criteria (30); increased waist circumference $\geq 102 \mathrm{~cm}$, elevated triglycerides $\geq 150 \mathrm{mg} / \mathrm{dl}$, reduced high-density lipoprotein (HDL) cholesterol $<40 \mathrm{mg} / \mathrm{dl}$, elevated blood pressure $\geq 130 / 85 \mathrm{mmHg}$ or treated hypertension, elevated glucose $\geq 100 \mathrm{mg} / \mathrm{dl}$. All the patients on lipid lowering therapy were correctly classified according to the MetS, taking into account, the present and past (before medication) lipid profiles. Sedentarity was assessed according to the following score (score 0 for at least $30 \mathrm{~min}$ exercise per week, score 1 for at least $30 \mathrm{~min}$ exercise 2-5 times per week, score 2 for at least $30 \mathrm{~min}$ exercise more than 5 times per week).

\section{Methods}

Serum glucose, cholesterol, triglycerides, HDL cholesterol, creatinine and SGPT were measured using an automate Kodak. Low-density lipoprotein (LDL) was calculated according to the Friedewald equation. The following hormone measurements were performed using commercially available RIA kits as follows: leptin (DSL, Webster, TX, USA; sensitivity $0.10 \mathrm{ng} / \mathrm{ml}$, intraassay coefficient of variation $4.9 \%$ ), adiponectin (LINCO Research, Inc, St Charles MO, USA; sensitivity $1 \mathrm{ng} / \mathrm{ml}$, intraassay coefficient of variation $<9.5 \%$ ), IGF-I (Nichols Diagnostics, San Juan Capistrano, CA, 
USA; sensitivity $6 \mathrm{ng} / \mathrm{ml}$, intraassay coefficient of variation $4.6 \%$ ), ultrasensitive estradiol (CIS Bio international, Gif-Sur-Yvette, France; sensitivity $1.36 \mathrm{pg} / \mathrm{ml}$, intraassay coefficient of variation $7.35 \%$ ). All radioimmunological measurements were performed in duplicate. Insulin, GH, total testosterone, SHBG, and dehydroepiandrosterone sulfate (DHEAS) were performed using commercial chemiluminescent assays (Immulite, DPC, Los Angeles, CA, USA). The respective sensitivities of the assays are $2 \mathrm{mIU} / \mathrm{ml}, 0.01 \mathrm{ng} / \mathrm{ml}$, $15 \mathrm{ng} / \mathrm{dl}, 0.2 \mathrm{nmol} / \mathrm{l}$ and $2 \mu \mathrm{g} / \mathrm{dl}$. Also, all the coefficients of variation were below $9 \%$.

Insulin sensitivity was estimated using the Quantitative Insulin Sensitivity Check Index (QUICKI) determined according to the equation QUICKI $=1 /(\log$ insulin $(\mathrm{mlU} / \mathrm{ml})+\log$ glucose $(\mathrm{mg} / \mathrm{dl}))$ (31). Low QUICKI indicates low insulin sensitivity, while high QUICKI indicates high insulin sensitivity. The freeandrogen index was calculated as total testosterone (converted to $\mathrm{nmol} / \mathrm{l}) / \mathrm{SHBG}(\mathrm{in} \mathrm{nmol} / \mathrm{l}) \times 10$.

\section{Statistical analysis}

SPSS version 13 was used to perform the statistical analysis. Differences in baseline clinical and biological characteristics between men with and without the MetS were tested for statistical significance with the Student's $t$-test and were indicated by the $\chi^{2}$-test. The Pearson coefficient was used for linear correlations between variables. Finally, and because variables are interrelated, a stepwise regression analysis was performed to find the most important explanatory variables for adiponectin and leptin. A $P$-value $<0.05$ was considered statistically significant for all analysis.

\section{Results}

The baseline clinical and biological characteristics of the 153 subjects included in the study are summarized in Table 1.

\section{Comparison of clinical and biological results according to the MetS (Table 1)}

In MetS + subjects, BMI, waist size, SBP and DBP values and the number of treated subjects for dyslipidemia $(P<0.0001, P<0.0001, P=0.004, P=0.009, P=0.03$ respectively) were significantly higher compared with metabolic syndrome negative (MetS-) individuals. Also, in the MetS + group, QUICKI, HDL cholesterol, adiponectin and $\mathrm{GH}$ were significantly lower $(P<0.0001, P<0.0001$, $P<0.0001$ and $P=0.005$ respectively), while triglycerides, leptin and SGPT were significantly higher $(P<0.0001, \quad P<0.0001, \quad P=0.002$ respectively $)$ compared with the MetS- group. Finally, testosterone and SHBG were statistically lower in MetS + subjects $(P=0.006$ and $P=0.004$ respectively).

\section{Baseline correlations between adipocytokines and markers of the metabolic syndrome}

Adiponectin and leptin were inversely correlated $(r=-0.23, \quad P<0.01)$. While adiponectin was positively correlated with age $(r=0.36, P<0.001)$ (Fig. 1A) and inversely correlated with BMI $(r=-0.36, P<0.001)$, leptin was only positively correlated with BMI $(r=0.55, P<0.001)$, with no statistically significant correlation with age. That is why the correlations of adiponectin with all the variables were adjusted for age and BMI, while the correlations of leptin were adjusted only for BMI (Tables 2 and 3).

Adiponectin was significantly correlated with waist size, triglycerides, HDL cholesterol and QUICKI $(r=-0.33,-0.26,0.45$ and $0.36, P<0.0001$ for all variables) (Fig. 1B). The relation between adiponectin and HDL cholesterol, triglycerides and QUICKI remained significant after adjustment for age and BMI. Leptin was also highly correlated with waist size and QUICKI $(r=0.63$ and -0.63 respectively, $P<0.001$ for both variables) (Fig. 2A). However, its relation to the lipid profile was weak (for cholesterol $r=0.16, P<0.05$; for triglycerides $r=0.17, P<0.05)$ and disappeared after adjustment for BMI. Leptin was also correlated with SBP and DBP $(r=0.18, P<0.05 ; r=0.24, P<0.01$ respectively); this relationship remained significant for DBP after adjustment for BMI.

\section{Baseline correlations between QUICKI, adipocytokines and sex steroids}

The QUICKI was correlated with total testosterone and SHBG $(r=0.35$ and 0.33 respectively, $P<0.001)$ with no significant correlation with the free-androgen index. This relationship remained significant after adjustment for BMI ( $r=0.215$ and 0.213 respectively; $P<0.01$ ). On the other hand, adiponectin was weakly correlated with total testosterone $(r=0.16, P<0.05)$, and strongly correlated with SHBG $(r=0.39, P<0.001)$ explaining its inverse and statistically significant relationship with the free-androgen index $(r=-0.24, P<0.01)$ (Fig. 1C). Because, in our population, SHBG was associated with waist size and BMI $(r=-0.25, P<0.01$, and $r=-0.32, P<0.001$ respectively), the relationship between SHBG and adiponectin was analyzed after adjustment for both waist and BMI. Adiponectin is still positively correlated with SHBG after adjustment for both variables $(r=0.33$ and $0.31, P<0.001)$ suggesting that the association between adiponectin and SHBG is independent of obesity. Also, adiponectin was inversely correlated with estradiol and DHEAS ( $r=-0.165, P<0.05 ; r=0.21, P<0.01$ respectively). However, after adjustment for age and BMI, all the correlations of adiponectin with sex steroids disappeared (testosterone, free-androgen index, DHEAS and estradiol) except the relationship with 
Table 1 Baseline biological characteristics of the study population.

\begin{tabular}{|c|c|c|c|c|}
\hline & All $(n=153)$ & $\begin{array}{l}\text { Subjects with the meta- } \\
\text { bolic syndrome } \\
\text { (MetS }+)(n=94)\end{array}$ & $\begin{array}{l}\text { Subjects without the } \\
\text { metabolic syndrome } \\
\text { (MetS }-)(n=59)\end{array}$ & Significance \\
\hline \multicolumn{5}{|l|}{ Clinical characteristics } \\
\hline Age (years) & $59.3 \pm 7.02$ & $58.8 \pm 6.41$ & $60.1 \pm 7.9$ & 0.25 \\
\hline BMI $\left(\mathrm{kg} / \mathrm{m}^{2}\right)$ & $27.3 \pm 3.6$ & $28.3 \pm 3.33$ & $25.6 \pm 3.57$ & $<0.0001$ \\
\hline Waist (cm) & $101.8 \pm 10.2$ & $105.3 \pm 8$ & $96.35 \pm 10.9$ & $<0.0001$ \\
\hline $\mathrm{SBP}(\mathrm{mmHg})$ & $129.3 \pm 12.3$ & $131.6 \pm 12.2$ & $125.8 \pm 11.7$ & 0.004 \\
\hline $\mathrm{DBP}(\mathrm{mmHg})$ & $79.7 \pm 7.8$ & $81 \pm 7.3$ & $77.6 \pm 8.3$ & 0.009 \\
\hline $\begin{array}{l}\text { Number of subjects with } \\
\text { coronaropathy }\end{array}$ & 23 & 15 & 8 & 0.69 \\
\hline $\begin{array}{l}\text { Number of hypertensive } \\
\text { subjects }\end{array}$ & 43 & 31 & 12 & 0.09 \\
\hline $\begin{array}{l}\text { Number of subjects treated } \\
\text { for dyslipidemia }\end{array}$ & 22 & 18 & 4 & 0.03 \\
\hline Number of current smokers & 58 & 40 & 18 & 0.14 \\
\hline Sedentarity score & $1.24 \pm 0.8$ & $1.21 \pm 0.81$ & $1.29 \pm 0.79$ & 0.57 \\
\hline \multicolumn{5}{|l|}{ Biological characteristics } \\
\hline Leptin $(\mathrm{ng} / \mathrm{ml})$ & $13.61+7.4$ & $15.8+6.8$ & $10.1+6.9$ & $<0.0001$ \\
\hline Adiponectin $(\mu \mathrm{g} / \mathrm{ml})$ & $8.03 \pm 4.51$ & $6.79 \pm 3.52$ & $9.99 \pm 5.20$ & $<0.0001$ \\
\hline Glucose $(\mathrm{mg} / 100 \mathrm{ml})$ & $103 \pm 10.2$ & $105.4 \pm 9.1$ & $98.7 \pm 10.4$ & $<0.0001$ \\
\hline QUICKI & $0.34 \pm 0.03$ & $0.33 \pm 0.02$ & $0.36 \pm 0.03$ & $<0.0001$ \\
\hline Total cholesterol $(\mathrm{mg} / \mathrm{dl})$ & $216 \pm 43$ & $221 \pm 44.4$ & $209 \pm 38.8$ & 0.13 \\
\hline Insulin $(\mu \mathrm{U} / \mathrm{ml})$ & $9.22 \pm 4.6$ & $10.5 \pm 4.8$ & $7.1 \pm 3.4$ & $<0.0001$ \\
\hline Triglycerides (mg/dl) & $168 \pm 80$ & $199 \pm 81.2$ & $119 \pm 48.1$ & $<0.0001$ \\
\hline HDL cholesterol $(\mathrm{mg} / \mathrm{dl})$ & $40+11$ & $36.2+8.9$ & $46+12.2$ & $<0.0001$ \\
\hline LDL cholesterol (mg/dl) & $143 \pm 37$ & $145.4 \pm 37.3$ & $140 \pm 35.1$ & 0.47 \\
\hline Creatinine $(\mathrm{mg} / \mathrm{l})$ & $9.44 \pm 1.71$ & $9.49 \pm 1.39$ & $9.39 \pm 2.11$ & 0.83 \\
\hline SGPT (UI/I) & $33.3 \pm 13.2$ & $36 \pm 13.8$ & $29 \pm 11.2$ & 0.002 \\
\hline $\mathrm{GH}(\mathrm{ng} / \mathrm{ml})$ & $0.52 \pm 0.96$ & $0.35 \pm 0.69$ & $0.80 \pm 1.23$ & 0.005 \\
\hline DHEAS (ng/dl) & $114.3 \pm 65.8$ & $116.1 \pm 73.4$ & $111.5 \pm 51.8$ & 0.68 \\
\hline Testosterone (ng/dl) & $383 \pm 117.6$ & $360.4 \pm 108.5$ & $412 \pm 116.1$ & 0.006 \\
\hline Free-androgen index & $3.89+1.3$ & $3.96+1.32$ & $3.79+1.26$ & 0.41 \\
\hline $\mathrm{SHBG}(\mathrm{nmol} / \mathrm{l})$ & $37.31 \pm 16.4$ & $34.0 \pm 13.7$ & $41.0 \pm 15.5$ & 0.004 \\
\hline Estradiol $(\mathrm{pg} / \mathrm{ml})$ & $29.3 \pm 12.3$ & $29 \pm 11.4$ & $29.5 \pm 12.9$ & 0.81 \\
\hline IGF-I (ng/ml) & $123.1 \pm 34.4$ & $122.1 \pm 35.3$ & $124.6 \pm 33.14$ & 0.65 \\
\hline
\end{tabular}

SHBG ( $r=0.20, P<0.005$ ) (Table 3). Finally, leptin was strongly inversely correlated with total testosterone and SHBG $(r=-0.44, P<0.001, r=-0.30, P<0.001$ respectively) (Fig. 2B). The relation of leptin with testosterone remained significant even after adjustment for BMI showing an independent relationship of leptin to testosterone (Table 2; Table 3).

\section{Baseline correlations between QUICKI, adipocytokines and the GH/IGF-I axis}

No significant relationship of either adiponectin or leptin with GH or IGF-I values was observed. QUICKI was weakly correlated with $\mathrm{GH}$ levels $(r=0.16$, $P=0.05)$ with no significant correlation with IGF-I

\section{Stepwise regression analysis}

A stepwise multiple regression analysis was used to look at the independent variables that may affect adiponectin and leptin. The variables entered in the model are the following: age, BMI, waist size, SBP, DBP, cholesterol, triglycerides, LDL cholesterol, HDL cholesterol, DHEAS, free-androgen index, testosterone, estradiol, GH, IGF-I, smoking status, sedentarity score and lipid lowering treatment. Leptin was also included in the regression when adiponectin was the dependent variable and vice versa. For adiponectin, HDL cholesterol, QUICKI, age and BMI $(P<0.0001, P=0.005, P=0.002$ and $P=0.047$ respectively) were the most important predictors; while for leptin, it was the QUICKI, waist and testosterone ( $P<0.0001, P<0.0001$ and $P=0.004$ respectively). The adjusted $R^{2}$ for the adiponectin and the leptin models were respectively 0.34 and 0.55 (Table 4).

\section{Discussion}

Using a population of 153 elderly non-diabetic men, we report here that both adiponectin and leptin are strongly associated with the MetS. Subjects with the MetS have lower adiponectin levels and higher leptin levels compared with subjects without the MetS. We found that adiponectin levels were inversely correlated with BMI, waist size and triglycerides and positively correlated with the QUICKI and with HDL cholesterol. The correlation with the QUICKI, triglycerides and HDL cholesterol remained significant even after adjustment for age and BMI, reinforcing the important independent 

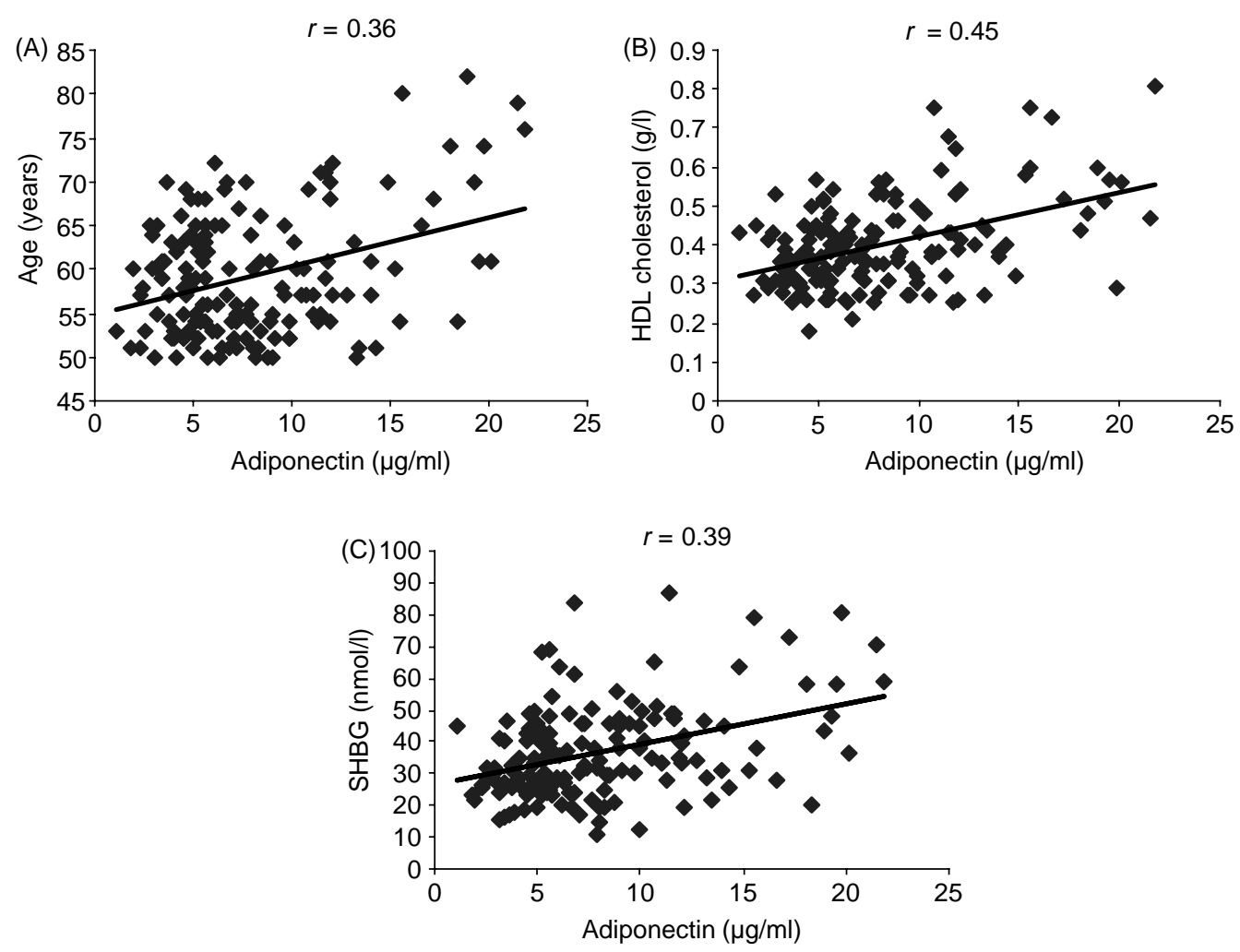

Figure 1 Correlations between plasma adiponectin and age (A), HDL cholesterol (B) and SHBG (C).

Table 2 Coefficients of correlations between leptin and the hormonal, metabolic and anthropometric factors (B1), and partial coefficients of correlations after correction for BMI (B2).

\begin{tabular}{|c|c|c|}
\hline & B1 & B2 \\
\hline Age (years) & 0.01 & $0.16^{*}$ \\
\hline BMI $\left(\mathrm{kg} / \mathrm{m}^{2}\right)$ & $0.55^{\star \star \star}$ & NA \\
\hline Waist $(\mathrm{cm})$ & $0.63^{\star \star \star}$ & $0.39^{\star \star \star}$ \\
\hline Adiponectin $(\mu \mathrm{g} / \mathrm{ml})$ & $-0.23^{\star \star}$ & -0.04 \\
\hline Glucose (mg/dl) & $0.27^{\star \star \star}$ & $0.24^{\star \star}$ \\
\hline Insulin $(\mu \mathrm{U} / \mathrm{ml})$ & $0.63^{\star \star \star}$ & $0.54^{\star \star *}$ \\
\hline QUICKI & $-0.63^{\star \star \star}$ & $-0.52^{\star \star \star}$ \\
\hline Total cholesterol (mg/dl) & $0.16^{\star}$ & 0.06 \\
\hline Triglycerides $(\mathrm{mg} / \mathrm{dl})$ & $0.17^{*}$ & 0.05 \\
\hline HDL cholesterol (mg/dl) & -0.05 & 0.07 \\
\hline LDL cholesterol $(\mathrm{mg} / \mathrm{dl})$ & 0.13 & 0.02 \\
\hline SGPT (UI/I) & $0.26^{\star *}$ & $0.18^{*}$ \\
\hline Creatinine (mg/l) & $0.19^{*}$ & $0.23^{\star \star}$ \\
\hline SBP $(\mathrm{mmHg})$ & $0.18^{*}$ & 0.09 \\
\hline $\mathrm{DBP}(\mathrm{mmHg})$ & $0.24^{\star \star}$ & $0.17^{*}$ \\
\hline Coronaropathy & $0.17^{*}$ & $0.21^{\star *}$ \\
\hline Testosterone (ng/dl) & $-0.44^{\star \star \star}$ & $-0.30^{\star \star \star}$ \\
\hline SHBG $(\mathrm{nmol} / \mathrm{l})$ & $-0.305^{\star \star \star}$ & -0.15 \\
\hline Free-androgen index & -0.11 & -0.13 \\
\hline Estradiol $(\mathrm{pg} / \mathrm{ml})$ & 0.08 & 0.03 \\
\hline DHEAS (ng/dl) & -0.11 & $-0.16^{\star}$ \\
\hline IGF-I (ng/ml) & -0.1 & 0.06 \\
\hline $\mathrm{GH}(\mathrm{ng} / \mathrm{ml})$ & -0.14 & -0.1 \\
\hline
\end{tabular}

${ }^{*} P<0.05 ;{ }^{* *} P<0.01 ;{ }^{* *} P<0.001$. relationship of adiponectin with the MetS. In addition, in the stepwise analysis, we found that age, HDL cholesterol, QUICKI and BMI are the most important predictors of adiponectin. Our results confirm the results of a previous study (32) in which the adiponectin relationship with insulin sensitivity and lipid profile (triglycerides and HDL) was found to be independent of body fat mass. Also, the strong relationship we found between adiponectin and the MetS components is consistent with the findings of two previous studies demonstrating the important role of intraabdominal fat in the prediction of adiponectin $(33,34)$. Finally, the relationship we found between adiponectin and age has been described previously $(32,35,36)$. A decrease in adiponectin clearance was proposed as the cause of this finding (35). However, in our study, adiponectin was not found to be correlated with creatinine levels even after adjustment for age and BMI. The explanation for the increase in adiponectin levels with aging should be determined.

We also found that the relationship of leptin with BMI and with the QUICKI is stronger than the relationship of adiponectin, but its relationship with the lipid parameters is weaker. After adjustment for BMI, the relationship of leptin with lipid parameters disappeared but remained strongly significant for the QUICKI. Similar to our results, the correlation between leptin and lipid parameters in the Baratta study (32) was entirely 
Table 3 Coefficients of correlations between adiponectin and the hormonal, metabolic and anthropometric factors (B1), and partial coefficients of correlations after correction for BMI (B2), age (B3) and both age and BMI (B4).

\begin{tabular}{|c|c|c|c|c|}
\hline & B1 & B2 & B3 & B4 \\
\hline Age (years) & $0.36^{\star \star \star}$ & $0.30^{\star \star \star}$ & NA & NA \\
\hline BMI $\left(\mathrm{kg} / \mathrm{m}^{2}\right)$ & $-0.36^{\star \star *}$ & NA & $-0.32^{\star \star \star}$ & NA \\
\hline Waist (cm) & $-0.33^{\star \star \star}$ & -0.08 & $-0.33^{\star \star \star}$ & -0.13 \\
\hline Glucose (mg/dl) & $-0.23^{\star \star}$ & $-0.20^{\star \star}$ & $-0.28^{\star \star \star}$ & $-0.25^{\star \star}$ \\
\hline Insulin $(\mu \mathrm{U} / \mathrm{ml})$ & $-0.28^{\star \star}$ & $-0.18^{\star}$ & $-0.30^{\star \star \star}$ & $-0.21^{\star *}$ \\
\hline QUICKI & $0.36^{\star \star \star}$ & $0.24^{\star *}$ & $0.35^{\star \star *}$ & $0.25^{\star \star \star}$ \\
\hline Total cholesterol $(\mathrm{mg} / \mathrm{dl})$ & 0.007 & 0.09 & -0.003 & 0.07 \\
\hline Triglycerides (mg/dl) & $-0.26^{\star \star \star}$ & $-0.19^{\star}$ & $-0.24^{\star \star}$ & $-0.18^{\star}$ \\
\hline HDL cholesterol (mg/dl) & $0.45^{\star \star \star}$ & $0.40^{\star \star \star}$ & $0.39^{\star \star \star}$ & $0.36^{\star \star *}$ \\
\hline LDL cholesterol (mg/dl) & -0.016 & 0.06 & -0.01 & 0.05 \\
\hline SGPT (UI/I) & $-0.25^{\star \star}$ & $-0.19^{\star}$ & $-0.16^{*}$ & -0.11 \\
\hline Creatinine (mg/l) & -0.04 & -0.05 & -0.07 & -0.07 \\
\hline $\mathrm{SBP}(\mathrm{mmHg})$ & 0.005 & 0.09 & -0.02 & 0.07 \\
\hline $\mathrm{DBP}(\mathrm{mmHg})$ & -0.003 & 0.07 & -0.02 & 0.15 \\
\hline Coronaropathy & -0.04 & -0.05 & -0.09 & -0.01 \\
\hline Testosterone $(\mathrm{ng} / \mathrm{dl})$ & $0.19^{*}$ & 0.05 & $0.20^{*}$ & 0.08 \\
\hline SHBG $(\mathrm{nmol} / \mathrm{l})$ & $0.39^{\star \star \star}$ & $0.31^{\star \star \star}$ & $0.27^{\star \star \star}$ & $0.20^{*}$ \\
\hline Estradiol (pg/ml) & $-0.165^{\star}$ & -0.14 & -0.14 & -0.12 \\
\hline Free-androgen index & $-0.245^{\star \star}$ & $-0.28^{\star \star \star}$ & -0.08 & -0.14 \\
\hline DHEAS (ng/dl) & $-0.21^{\star \star}$ & $-0.20^{\star}$ & -0.07 & -0.09 \\
\hline IGF-I (ng/ml) & -0.06 & -0.07 & 0.07 & 0.033 \\
\hline $\mathrm{GH}(\mathrm{ng} / \mathrm{ml})$ & 0.11 & 0.09 & 0.007 & 0.007 \\
\hline
\end{tabular}

NA, not applicable; ${ }^{\star} P<0.05 ;{ }^{\star \star} P<0.01 ;{ }^{\star \star *} P<0.001$.

mediated by BMI. On the other hand, the strong relationship which we and others (22) found between insulin sensitivity and leptin, independent of BMI, could explain the fact that leptin is an independent risk factor for coronary heart disease as was shown in the WOSCOPS study (15). For this reason, it was proposed (22) that relative (BMI-corrected) hyperleptinemia may be a new component of the MetS and one can speculate that subjects with relative hyperleptinemia develop their MetS at an earlier stage. Surprisingly, the results of the Baratta study (32) differed from our results and the correlation between leptin and insulin sensitivity was found, in that study, to be mediated entirely by BMI. This difference from our results could be explained by gender or other unknown differences related to their population characteristics; in the Baratta study, the major part of the population was females. Further studies are needed to define the factors that may influence the relationship of leptin with insulin resistance.

We also looked at the relationship of both QUICKI and adipocytokines with sex steroids. We found that the QUICKI was correlated with total testosterone and SHBG but not with the free-androgen index; this relation was independent of BMI. Previous studies on the relationship between androgens and insulin sensitivity gave conflicting results depending on whether total or free testosterone was measured. One explanation for this discrepancy is that SHBG is mediating the link between testosterone and insulin sensitivity. In fact, insulin exerts an inhibitory effect on the SHBG production by the liver (37). An alternative explanation is that the assays used to measure free testosterone have methodological limitations. Low endogenous testosterone levels in healthy men are positively associated with higher
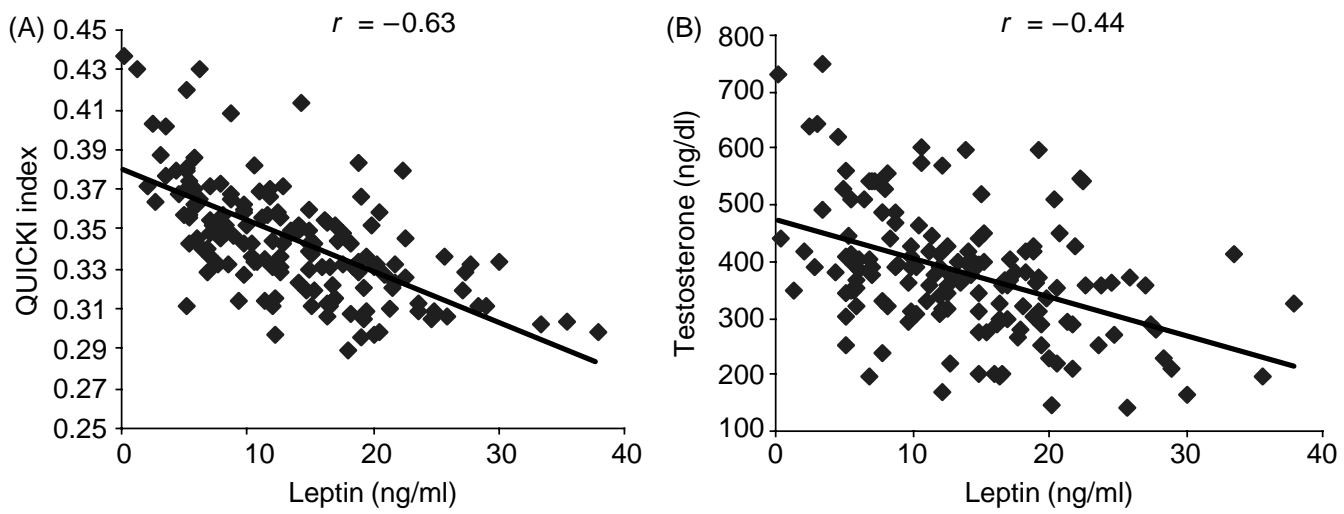

Figure 2 Correlations between plasma leptin and (A) QUICKI index and (B) testosterone. 
Table 4 Multiple regression analysis with stepwise analysis with adiponectin (A) and leptin (B) as dependent variables.

\begin{tabular}{|c|c|c|c|}
\hline A & Parameter estimate & Std. error & Significance \\
\hline HDL cholesterol & 12.7 & 2.91 & $<0.0001$ \\
\hline QUICKI & 32.5 & 11.41 & 0.005 \\
\hline Age & 0.143 & 0.046 & 0.002 \\
\hline $\mathrm{BMI}$ & -0.197 & 0.099 & 0.047 \\
\hline B & Parameter estimate & Std. error & Significance \\
\hline $\begin{array}{l}\text { QUICKI } \\
\text { Waist }\end{array}$ & $\begin{array}{c}-91.26 \\
0.281\end{array}$ & $\begin{array}{c}16.68 \\
0.048\end{array}$ & $\begin{array}{l}<0.0001 \\
<0.0001\end{array}$ \\
\hline Testosterone & -0.012 & 0.004 & 0.004 \\
\hline
\end{tabular}

cardiovascular risk profile (BMI, waist-to-hip ratio, lipid profile (38), insulin resistance (39-42)) and with an increased risk of future development of diabetes (43). This relationship was found to be independent of age, obesity, and body fat distribution $(44,45)$. In contrast, data on the relationship between free testosterone levels and insulin sensitivity are conflicting, with two studies showing no correlation $(46,47)$, whereas a third study demonstrates a weak positive relationship (40). In addition, and most likely as a result of reducing body fat, testosterone therapy has been shown to reduce LDL (48) and to improve insulin sensitivity (49). Thus, the relationship we found between QUICKI and total testosterone is in line with the previous literature. Also, the absence of correlation that we found between the free-androgen index and QUICKI confirms the results of the two previous studies mentioned above $(46,47)$. Finally, we found lower testosterone and SHBG levels in subjects with the MetS compared with subjects without the MetS. This finding was also recently described in middle-aged men in whom testosterone and SHBG predicts the MetS and diabetes (43). We also looked at the relationship of both leptin and adiponectin with sex steroids. We found that leptin was strongly inversely correlated with testosterone and SHBG, but not with the free-androgen index. After adjustment for BMI, the relationship of leptin with testosterone is maintained, despite its disappearance with SHBG. Also, in our results, testosterone was found to be a strong predictor of leptin in the stepwise regression analysis reinforcing the independent important inverse relationship between leptin and testosterone. The relationship between leptin and testosterone in the elderly population has not been extensively studied. An inverse relation between both variables has previously been reported in cross-sectional studies (20-22). In addition, testosterone therapy reduces serum leptin concentrations in subjects with low testosterone levels (50). The explanation for that relationship is the presence of functional leptin receptors in reproductive tissues. Even if the exact role of leptin is not fully understood, it is involved in normal sexual maturation and reproduction (51). More interesting was the relationship between adiponectin and sex steroids. Adiponectin was found to be correlated with both total testosterone and SHBG, with a much stronger relationship with SHBG, the result being a statistically inverse correlation with the free-androgen index. The strong relationship of adiponectin to SHBG was persistent after adjustment for age, waist or BMI suggesting that there is a direct link between SHBG and adiponectin, independent of obesity. Our report is the first to show this strong relationship in a male population. In another recent report, in women with polycystic ovary disease, adiponectin concentrations correlated positively with serum SHBG and testosterone (52). Adiponectin may directly stimulate SHBG secretion by the liver, the opposite of the inhibitory effect of insulin on SHBG (37). On the other hand, previous studies have shown that adiponectin is higher in hypogonadal men compared with eugonadal men (18) and has been reduced $(18,53)$ or not $(19)$ by testosterone therapy in men with low testosterone. The inverse relationship we found between adiponectin and both the free-androgen index and DHEAS is in line with the above findings. Those results suggest that, in male hypogonadism, the insulin resistant state is not mediated by low adiponectin levels. We speculate that, besides the direct effect of adiponectin on SHBG, there is a strong inhibitory effect of androgens (free testosterone and DHEAS) on adiponectin levels. We think that there is a need to look at the genetic regulation of the adiponectin gene by androgens. We also found an inverse relationship between adiponectin and estradiol. This relationship disappears after adjustment for both age and BMI. The relationship of adiponectin to estradiol is controversial; adiponectin has been proven to be gender dependent, with higher levels in women than in men $(16,17)$. While some authors found no effect of estrogens on adiponectin (16), Gavrila et al. (54) have recently found a negative relationship between both variables in women.

Finally, we did not find in our population any relationship between either adiponectin or leptin and GH or IGF-I levels. The relationship between insulin sensitivity and the GH/IGF-I axis is still controversial. The increased cardiovascular mortality associated with hypopituitarism (55) was partly attributed to untreated GH deficiency mainly because of the adverse serum lipid patterns. However, in GH-deficient subjects, GH treatment results in improved (56) or worsening (57) insulin sensitivity depending on the $\mathrm{GH}$ doses, with a worsening at higher doses. Even in healthy adults, the metabolic effects of GH are dose- and gender-dependent, with the standard adult GH deficiency replacement dose inducing insulin resistance, whereas lower doses improved insulin sensitivity, especially in males (58). Compared with subjects without the MetS, we found that those with MetS had lower baseline GH but no differences in IGF-I levels. Even if this finding was not described in the MetS, it has previously been described in obesity, where basal and total 24-h GH levels are decreased (59). A defect in the hypothalamic-pituitary axis or an increase in the somatostatin inhibitory action might be 
contributing factors for this finding (59). Studies looking at the effect of GH therapy on adipocytokines are also conflicting. Although GH-deficient subjects displayed several metabolic abnormalities associated with low adiponectin (such as high BMI, visceral adiposity), adiponectin was not found to be lower in GH-deficient subjects compared with controls (27). However, the long-term treatment by recombinant human growth hormone induced a slight statistically significant increment in adiponectin (27). This slight increase was also observed in another study only in women (26), while a third study did not show any effect (28). Finally, the interaction between serum leptin and the IGF-I system was also recently studied both in men and women. There was a significant correlation between leptin and free IGF-I but not with total IGF-I in men (60). This difference from our results could be explained by the fact that, in our study, the total, but not the free IGF-I was measured. Also, the absence of a relationship between adipocytokines and GH/IGF-I that we found may be related to the normal IGF-I axis in our study population; thus small modifications of adiponectin and leptin may not be detected.

In conclusion, the new relationships we described between adiponectin and androgens are of great interest. We speculate that adiponectin directly stimulates SHBG secretion by the liver. Also, the direct inverse relationship we found between the free-androgen index and adiponectin suggests that testosterone downregulates the expression of the adiponectin gene. In addition, the strong relationship we found between leptin and QUICKI, independent of BMI, reinforces the need to define the factors (gender, ethnic or others) that may influence the relationship of leptin with insulin resistance. Further studies are needed to fully elucidate the above findings.

\section{Acknowledgement}

This work was supported by a grant from the "Conseil de Recherche de l'Université Saint-Joseph” (FM 99).

\section{References}

1 Pittas AG, Joseph NA \& Greenberg AS. Adipocytokines and insulin resistance. Journal of Clinical Endocrinology and Metabolism 2004 $89447-452$.

2 Kershaw EE \& Flier JS. Adipose tissue as an endocrine organ. Journal of Clinical Endocrinology and Metabolism 200489 $2548-2556$.

3 Goldstein BJ \& Scalia R. Adiponectin: a novel adipokine linking adipocytes and vascular function. Journal of Clinical Endocrinology and Metabolism $2004892563-2568$.

4 Arita Y, Kihara S, Ouchi N, Takahashi M, Maeda K, Miyagawa J, Hotta K, Shimomura I, Nakamura T, Miyaoka K, Kuriyama H, Nishida M, Yamashita S, Okubo K, Matsubara K, Muraguchi M, Ohmoto Y, Funahashi T \& Matsuzawa Y. Paradoxical decrease of an adipose specific protein, adiponectin, in obesity. Biochemical and Biophysical Research Communications 1999257 79-83.
5 Weyer C, Funahashi T, Tanaka S, Hotta K, Matsuzawa Y, Pratley RE \& Tataranni PA. Hypoadiponectinemia in obesity and type 2 diabetes: close association with insulin resistance and hyperinsulinemia. Journal of Clinical Endocrinology and Metabolism 200186 1930-1935.

6 Matsubara M, Maruoko S \& Katayose S. Decreased plasma adiponectin concentrations in women with dyslipidemia. Journal of Clinical Endocrinology and Metabolism $2002 \mathbf{8 7}$ 2764-2769.

7 Hotta K, Funahashi T, Arita Y, Takahashi M, Matsuda M, Okamoto Y, Iwahashi H, Kuriyama H, Ouchi N, Maeda K, Nishida M, Kihara S, Sakai N, Nakajima T, Hasegawa K, Muraguchi M, Ohmoto Y, Nakamura T, Yamashita S, Hanafusa T \& Matsuzawa Y. Plasma concentrations of a novel adipose-specific protein, adiponectin, in type 2 diabetic patients. Arteriosclerosis, Thrombosis and Vascular Biology 200020 1595-1599.

8 Nakamura Y, Shimada K, Fukuda D, Shimada Y, Ehara S, Hirose M, Kataoka T, Kamimori K, Shimodozono S, Kobayashi Y, Yoshiyama M, Takeuchi K \& Yoshikawa J. Implications of plasma concentrations of adiponectin in patients with coronary artery disease. Heart 200490 528-533.

9 Rothenbacher D, Brenner H, Marz W \& Koenig W. Adiponectin, risk of coronary heart disease and correlations with cardiovascular risk markers. European Heart Journal 200526 1640-1646.

10 Xydakis AM, Case CC, Jones PH, Hoogeveen RC, Liu MY, Smith EO, Nelson KW \& Ballantyne CM. Adiponectin, inflammation and the expression of the metabolic syndrome in obese individuals: the impact of rapid weight loss through caloric restriction. Journal of Clinical Endocrinology and Metabolism 200489 2697-2703.

11 Spranger J, Kroke A, Mohlig M, Bergmann MM, Ristow M, Boeing $\mathrm{H} \&$ Pfeiffer AF. Adiponectin and protection against type 2 diabetes mellitus. Lancet $2003361226-228$.

12 Bjorbaek C \& Kahn BB. Leptin signalling in the central nervous system and the periphery. Recent Progress in Hormone Research 200459 305-311.

13 Considine RV, Sinha MK, Heiman ML, Kriauciunas A, Stephens TW, Nyce MR, Ohannesian JP, Marco CC, McKee LJ \& Bauer TL. Serum immunoreactive-leptin concentrations in normal-weight and obese humans. New England Journal of Medicine $1996334292-295$.

14 Sader S, Nian M \& Liu P. Leptin: a novel link between obesity, diabetes, cardiovascular risk, and ventricular hypertrophy. Circulation 2003108 644-646.

15 Wallace AM, McMahon AD, Packard CJ, Kelly A, Shepherd J, Gaw A \& Sattar N. Plasma leptin and the risk of cardiovascular disease in the West of Scotland Coronary Prevention Study (WOSCOPS). Circulation 2001104 3052-3056.

16 Nishizawa H, Shimomura I, Kishida K, Maeda N, Kuriyama H, Nagaretani H, Matsuda M, Kondo H, Furuyama N, Kihara S, Nakamura T, Tochino Y, Funahashi T \& Matsuzawa Y. Androgens decrease plasma adiponectin, an insulin-sensitizing adipocytederived protein. Diabetes $2002 \mathbf{5 1} 2734-2741$.

17 Yamamoto Y, Hirose H, Saito I, Tomita M, Taniyama M, Matsubara K, Okazaki Y, Ishii T, Nishikai K \& Saruta T. Correlation of the adipocyte-derived protein adiponectin with insulin resistance index and serum high-density lipoprotein-cholesterol, independent of body mass in the Japanese population. Clinical Science 2002103 137-142.

18 Lanfranco F, Zitzmann M, Simoni M \& Nieschlag E. Serum adiponectin levels in hypogonadal men: influence of testosterone replacement therapy. Clinical Endocrinology $2004 \mathbf{6 0}$ 500-507.

19 Page ST, Amory JK, Bowman FD, Anawalt BD, Matsumoto AM, Bremner WJ \& Tenover JL. Exogenous testosterone (T) alone or with finasteride increases physical performance, grip strength, and lean body mass in older men with low serum T. Journal of Clinical Endocrinology and Metabolism 200590 1502-1510.

20 Behre HM, Simoni M \& Nieschlag E. Strong association between serum levels of leptin and testosterone in men. Clinical Endocrinology 199747 237-240. 
21 Luukkaa V, Pesonen U, Huhtaniemi I, Lehtonen A, Tilvis R, Tuomilehto J, Koulu M \& Huupponen R. Inverse correlation between serum testosterone and leptin in men. Journal of Clinical Endocrinology and Metabolism 199883 3243-3246.

22 Buettner R, Bollheimer LC, Zietz B, Drobnik W, Lackner K, Schmitz G, Scholmerich J \& Palitzsch KD. Definition and characterization of relative hypo- and hyperleptinemia in a large Caucasian population. Journal of Endocrinology 2002175 745-756.

23 Ronchi CL, Corbetta S, Cappiello V, Morpurgo PS, Giavoli C, BeckPeccoz P, Arosio M \& Spada A. Circulating adiponectin levels and cardiovascular risk factors in acromegalic patients. European Journal of Endocrinology 2004150 663-669.

24 Silha JV, Krsek M, Hana V, Marek J, Jezkova J, Weiss V \& Murphy LJ. Perturbations in adiponectin, leptin and resistin levels in acromegaly: lack of correlation with insulin resistance. Clinical Endocrinology 200358 736-742.

25 Lam KS, Xu A, Tan KC, Wong LC, Tiu SC \& Tam S. Serum adiponectin is reduced in acromegaly and normalized after correction of growth hormone excess. Journal of Clinical Endocrinology and Metabolism 200489 5448-5453.

26 Engstrom BE, Burman P, Holdstock ZC \& Karisson FA. Effects of growth hormone $(\mathrm{GH})$ on ghrelin, leptin, and adiponectin in $\mathrm{GH}$ deficient patients. Journal of Clinical Endocrinology and Metabolism 200388 5193-5198.

27 Giavoli C, Cappiello V, Corbetta S, Ronchi CL, Morpurgo PS, Ferrante E, Beck-Peccoz P \& Spada A. Different effects of short-and long-term recombinant hGH administration on ghrelin and adiponectin in GH-deficient adults. Clinical Endocrinology 2004 $6181-87$.

28 Hana V, Silha JV, Justova V, Lacinova Z, Stepan JJ \& Murphy LJ. The effects of $\mathrm{GH}$ replacement in adult $\mathrm{GH}$-deficient patients: changes in body composition without concomitant changes in the adipokines and insulin resistance. Clinical Endocrinology 2004 $60442-450$.

29 Alberti KG \& Zimmet P. Definition, diagnosis and classification of diabetes mellitus and its complications. Part 1: diagnosis and classification of diabetes mellitus provisional report of a WHO consultation. Diabetes Medicine 1998 15 539-553.

30 National Cholesterol Education Program (NCEP). Expert panel on detection, evaluation, and treatment of high blood cholesterol in adults (Adult Treatment Panel III final report). Circulation 2002 106 3413-3421.

31 Hrebicek J, Janout V, Malincikova J, Horakova D \& Cizek L. Detection of insulin resistance by simple quantitative insulin check index QUICKI for epidemiological assessment and prevention. Journal of Clinical Endocrinology and Metabolism $2002 \mathbf{8 7}$ 144-147.

32 Baratta R, Amato S, Degano C, Farina MG, Patane G, Vigneri R \& Frittitta L. Adiponectin relationship with lipid metabolism is independent of body fat mass: evidence from both cross-sectional and intervention studies. Journal of Clinical Endocrinology and Metabolism 200489 2665-2671.

33 Cnop M, Havel PJ, Utzschneider KM, Carr DB, Sinha MK, Boyko EJ, Retzlaff BM, Knopp RH, Brunzell JD \& Kahn SE. Relationship of adiponectin to body fat distribution, insulin sensitivity and plasma lipoproteins: evidence for independent roles of age and sex. Diabetologia $2003 \mathbf{4 6} 459-469$.

34 Cote M, Mauriege P, Bergeron J, Almeras N, Tremblay A, Lemieux I \& Despres JP. Adiponectinemia in visceral obesity: Impact on glucose tolerance and plasma lipoprotein and lipid levels in men. Journal of Clinical Endocrinology and Metabolism 200590 1434-1439.

35 Isobe T, Saitoh S, Takagi S, Takeuchi H, Chiba Y, Katoh N \& Shimamoto K. Influence of gender, age and renal function on plasma adiponectin level: the Tanno and Sobetsu study. European Journal of Endocrinology 2005153 91-98.

36 Adamczak M, Rzepka E, Chudek J \& Wiecek A. Ageing and plasma adiponectin concentration in apparently healthy males and females. Clinical Endocrinology $2005 \mathbf{6 2} 114$.
37 Plymate SR, Mateg LA, Jones RE \& Friedl KE. Inhibition of sex hormone-binding globulin production in the human hepatoma (Hep G2) cell line by insulin and prolactin. Journal of Clinical Endocrinology and Metabolism 1988 67 460-464.

38 Simon D, Charles MA, Nahoul K, Orssaud G, Kremski J, Hully V, Joubert E, Papoz L \& Eschwege E. Association between plasma total testosterone and cardiovascular risk factors in healthy adult men: the Telecom study. Journal of Clinical Endocrinology and Metabolism 199782 682-685.

39 Oh JY, Barrett-Connor E, Wedick NM \& Wingard DL. Endogenous sex hormones and the development of type 2 diabetes in older men and women: the Rancho Bernardo study. Diabetes Care 200225 55-60.

40 Haffner SM, Karhapaa P, Mykkanen L \& Laakso M. Insulin resistance, body fat distribution, and sex hormones in men. Diabetes $199443212-219$.

41 Simon D, Preziosi P, Barrett-Connor E, Roger M, Saint-Paul M, Nahoul K \& Papoz L. Interrelation between plasma testosterone and plasma insulin in healthy adult men: the Telecom Study. Diabetologia 199235 173-177.

42 Pitteloud N, Mootha VK, Dwyer AA, Hardin M, Lee H, Eriksson KF, Tripathy D, Yialamas M, Groop L, Elahi D \& Hayes FJ. Relationship between testosterone levels, insulin sensitivity, and mitochondrial function in men. Diabetes Care 200528 1636-1642.

43 Laaksonen DE, Niskanen L, Punnonen K, Nyysonen K, Tuomainen T-P, Valkonen V-P, Salonen R \& Salonen JT. Testosterone and sex hormone-binding globulin predict the metabolic syndrome and diabetes in middle-aged men. Diabetes Care 200427 1036-1041.

44 Seidell JC, Bjorntorp P, Sjostrom L, Kvist H \& Sannerstedt R. Visceral fat accumulation in men is positively associated with insulin, glucose, and C-peptide levels, but negatively with testosterone levels. Metabolism - Clinical and Experimental 1990 39 897-901.

45 Pasquali R, Casimirri F, Cantobelli S, Melchionda N, Morselli Labate AM, Fabbri R, Capelli M \& Bortoluzzi L. Effect of obesity and body fat distribution on sex hormones and insulin in men. Metabolism - Clinical and Experimental 199140 101-104.

46 Birkeland KI, Hanssen KF, Torjesen PA \& Vaaler S. Level of sex hormone-binding globulin is positively correlated with insulin sensitivity in men with type 2 diabetes. Journal of Clinical Endocrinology and Metabolism 199376 275-278.

47 Abate N, Haffner SM, Garg A, Peshock RM \& Grundy SM. Sex steroid hormones, upper body obesity, and insulin resistance. Journal of Clinical Endocrinology and Metabolism $2002 \quad \mathbf{8 7}$ 4522-4527.

48 Tenover JS. Effect of testosterone supplementation in the aging male. Journal of Clinical Endocrinology and Metabolism $1992 \mathbf{7 5}$ 1092-1098.

49 Marin P, Holmang S, Jonsson L, Sjostrom L, Kvist H, Holm G, Lindstedt G \& Bjorntorp P. Androgen treatment of abdominally obese men. International Journal of Obesity and Related Metabolic Disorders $199216991-997$.

50 Sih R, Morley JE, Kaiser FE, Perry HM, 3rd, Patrick P \& Ross C. Testosterone replacement in older hypogonadal men: a 12-month randomized controlled trial. Journal of Clinical Endocrinology and Metabolism 199782 1661-1667.

51 Caprio M, Fabbrini E, Isodori AM, Aversa A \& Fabbri A. Leptin in reproduction. Trends in Endocrinology and Metabolism 200112 65-72.

52 Ardawi MS \& Rouzi AA. Plasma adiponectin and insulin resistance in women with polycystic ovary disease. Fertility and Sterility 2005 83 1708-1716.

53 Page ST, Herbst KL, Amory JK, Coviello AD, Anawalt BD, Matsumoto AM \& Bremner WJ. Testosterone administration suppresses adiponectin levels in men. Journal of Andrology 2005 26 85-92.

54 Gavrila A, Chan JL, Yiannakouris N, Kontogianni M, Miller LC, Orlova C \& Mantzoros CS. Serum adiponectin levels are inversely associated with overall and central fat distribution but are not 
directly regulated by acute fasting or leptin administration: crosssectional and interventional studies. Journal of Clinical Endocrinology and Metabolism $2003 \mathbf{8 8} 4823-4831$.

55 Tomlinson W \& Holden N. Association between premature mortality and hypopituitarism. Lancet 2001357 425-431.

56 Hwu CM, Kwok CF, Lai TY, Shih KC, Lee TS, Hsiao LC, Lee SH, Fang VS \& Ho LT. Growth hormone (GH) replacement reduces total body fat and normalizes insulin sensitivity in GH-deficient adults: a report of one year clinical experience. Journal of Clinical Endocrinology and Metabolism 199782 3285-3292.

57 Bramnert M, Segerlantz M, Laurila E, Daugaard JR, Manhem P \& Groop L. Growth hormone replacement therapy induces insulin resistance by activating the glucose-fatty acid cycle. Journal of Clinical Endocrinology and Metabolism 200388 1455-1463.

58 Yuen K, Ong K, Husbands S, Chatelain P, Fryklund L, Gluckman P, Ranke M, Cook D, Rosenfeld R, Wass J \& Dunger D. The effects of short-term administration of two low doses versus the standard
GH replacement dose on insulin sensitivity and fasting glucose levels in young healthy adults. Journal of Clinical Endocrinology and Metabolism 200287 1989-1995.

59 Kokkoris P \& Pi-Sunyer FX. Obesity and endocrine disease. Endocrinology and Metabolism Clinics of North America 200332 895-914.

60 Gomez JM, Maravall FJ, Gomez N, Navarro MA, Casamitjana R \& Soler J. Interactions between serum leptin, the insulin-like growth factor-I system, and sex, age, anthropometric and body composition variables in a healthy population randomly selected. Clinical Endocrinology 200358 213-219.

Received 2 November 2005

Accepted 31 March 2006 